\title{
Blood Transfusion Profile of Beta Thalassemia Major Patients Attending a Tertiary Care Hospital
}

\author{
Mallikarjun. A. Pattanashetti ${ }^{1 *}$, Ganga S. Pilli ${ }^{2}$ and Laxmi A Pattanashetti ${ }^{3}$ \\ ${ }^{1}$ Department of Pathology, S. Nijalingappa Medical College and HSK Hospital and Medical Research Centre, Bagalkot, Karnataka, India \\ ${ }^{2}$ Department of Pathology, KLE University’s Jawaharlal Nehru Medical College, Belagavi. Karnataka, India \\ ${ }^{3}$ Department of Pharmacology, KLE College of Pharmacy, Nehru Nagar, Belagavi, Karnataka, India
}

\begin{abstract}
Background: Beta $(\beta)$ thalassemia major is most common monogenic disorder in the world. Around 1,00,000 children are born each year with the severe homozygous state of the disease in India. The objectives of this study was to assess clinical data and the blood transfusion profile of Beta thalassemia major patients attending tertiary care hospital. This was undertaken as very few studies have been done in this region of the vast country.
\end{abstract}

Methods: The study was done at a tertiary care teaching hospital from January 2014 to December 2014. Universal sampling method was used and $35 \beta$ thalassemia major patients who received blood transfusions at 2 to 4 weeks interval in the hospital were included in this study. Clinical details and blood transfusion record was collected on proforma for all patients and data interpreted.

Result: Males (80\%) outnumbered females (20\%) with male to female ratio of $4: 1$. Nearly half of the study population was aged between 10 to 12 years (51.43). Majority of the patients had one blood transfusion per month $(91.43 \%)$ and were on chelation therapy $(71.43 \%)$. Majority of the patients received 100 to 125 blood transfusions during their lifetime (28.57\%). Least number of blood transfusions of more than 250 transfusions was taken by one patient $(2.86 \%)$.

Conclusion: The present study describes the transfusion profile of $\beta$ thalassemia major patients attending the tertiary care hospital and emphasizes on maintenance of transfusion record of $\beta$ thalassemia major patients for better management of these patients.

Keywords: B Thalassemia; Transfusion; Chelation.

\section{Introduction}

Beta $(\beta)$ thalassemia syndromes are a group of hereditary blood disorders characterized by reduced or absent $\beta$ globin chain synthesis, resulting in reduced hemoglobin $(\mathrm{Hb})$ in red blood cells $(\mathrm{RBC})$, decreased $\mathrm{RBC}$ production and anemia. Most thalassemias are inherited as recessive traits. $\beta$ thalassemia is caused by the reduced $\left(\beta^{+}\right)$or absent $\left(\beta^{0}\right)$ synthesis of the $\beta$ globin chains of the hemoglobin tetramer, which is made up of two $\alpha$ globin and two $\beta$ globin chains $\left(\alpha_{2} \beta_{2}\right)$. Three clinical and hematological conditions of increasing severity are recognized, i.e., $\beta$ thalassemia carrier state, thalassemia intermedia, and thalassemia major. ${ }^{[1]}$

Although reliable data are still lacking for many regions of the world, recent data indicate that about $7 \%$ of the world's population is a carrier of a hemoglobin disorder, and that $3,00,000-5,00,000$ children are born each year with the severe homozygous state of the disease worldwide. ${ }^{[1]}$ Every year approximately 1,00,000 are born with thalassemia in India ${ }^{[2]}$ The carrier rate for thalassemia gene varies from $1-3 \%$ in southern India to $3-15 \%$ in Northern India. ${ }^{[3]}$
These patients with BTM require regular blood transfusions to survive. Regular transfusion with packed red cells is recommended to maintain a pretransfusion hemoglobin threshold not exceeding $9.5 \mathrm{~g} / \mathrm{dl}$, which seems to be associated with adequate marrow inhibition and a relatively low iron burden. ${ }^{[6]}$ Transfusions should generally be given at an interval of three to four weeks. Transfusions should be scheduled in advance and maintained at a fixed schedule. This enables patients and families to establish routines and will improve quality of life. In patients with severe anemia (hemoglobin less than $5 \mathrm{~g} / \mathrm{dL}$ ) or cardiac compromise, the rate of transfusion should be reduced to $2 \mathrm{~mL} / \mathrm{kg}$ per hour to avoid fluid overload. Diuretics such as furosemide (1 to $2 \mathrm{mg} / \mathrm{kg}$ ) may be necessary for some patients. If cardiac insufficiency is present, higher pretransfusion hemoglobin levels ( 10 to $12 \mathrm{~g} / \mathrm{dL}$ ) should be maintained with smaller volume transfusions given every one to two weeks. The only curative treatment for this disease at present is bone marrow transplantation or stem cell transplantation. Management of thalassemia is through lifelong blood transfusion and iron chelation therapy. Even this conventional treatment is often unavailable for patients in remote areas. 
There is lack of studies in this region of country describing blood transfusion profile of $\beta$ thalassemia major patients. Hence, the present study was undertaken to assess the blood transfusion profile of these patients.

\section{Materials and Methods}

The present cross-sectional study was done at a tertiary care hospital from January 2014 to December 2014. Universal sampling method was used and $35 \beta$ thalassemia major patients who received blood transfusions were selected during the study period. Prior to the commencement, ethical clearance for the study was obtained from the Institute ethics committee.

The objectives of this study were to assess the clinical data and transfusion record of these patients. All known diagnosed cases of $\beta$ thalassemia major who were 10 years of age and above, and have received blood transfusions at two to four weeks intervals with or without iron chelation therapy in the tertiary care hospital were included. Patients who are known cases of other types of thalassemias and hemoglobinopathies and patients on transfusion dependent anemia other than $\beta$ thalassemia were excluded from the study. Written informed consent was obtained from the selected patients. These patients were interviewed for the demographic details and history of disease. The clinical examination was done for all patients. Blood transfusion data was collected in detail. Proforma consisted of data regarding total number of blood transfusions during lifetime, number of transfusions per month and Chelation therapy.

The data obtained was coded and entered into Microsoft Excel Spreadsheet. The data was analysed using SPSS version 20. Categorical data was expressed in terms of rates, ratios and percentage. Continuous data was expressed as Mean \pm standard deviation, median and range.

\section{Result}

A total of 35 patients registered under Blood Bank with $\beta$ thalassemia major were included in the study. On physical examination splenomegaly and hepatomegaly were present among $65.71 \%$ and $14.29 \%$ of the patients respectively. In the present study, the mean age was 13.46 \pm 3.67 years and median age was 12 years with younger patients being 10 years and oldest being 23 years as shown in Table I. Majority ( $80 \%)$ of the patients were males and the male to female ratio was $4: 1$. The mean duration of disease was $12.29 \pm 3.66$ years and the mean total number of transfusions was $151.4 \pm 45.65$ among all the patients as shown in Table II.

The commonest age group was 10 to 12 years, comprised of $51.43 \%$ of the patients followed by $13-15$ years age group $(25.71 \%)$. Most of the patients were aged between 7 to 12 months $(45.71 \%)$ and 12 to 18 months $(42.86 \%)$ at the diagnosis of $\beta$ thalassemia major . The history of splenectomy was noted in $17.14 \%$ of the patients. Majority of the patients received one transfusion per month $(91.43 \%)$ as shown in Table III. Majority $(71.43 \%)$ of patients were on chelation therapy. Majority of the patients received one transfusion per month $(91.43 \%)$ and majority of the patients received 100 to 125 blood transfusions during their lifetime $(28.57 \%)$ followed by 126 to 150 blood transfusions (22.86 \%) as shown in Table II. Least number of blood transfusions of more than 250 transfusions was taken by one patient (2.86 \%) as shown in Table III.

\section{Table I:}

\begin{tabular}{|c|c|c|c|c|c|}
\hline \multirow{2}{*}{ Variable } & \multirow[b]{2}{*}{ Mean } & \multirow[b]{2}{*}{ SD } & \multirow{2}{*}{ Median } & \multicolumn{2}{|c|}{ Range } \\
\hline & & & & Min & Max \\
\hline Age (Years) & 13.46 & 3.67 & 12 & 10 & 23 \\
\hline Age at diagnosis (Months) & 8.94 & 6.15 & 8 & 3 & 36 \\
\hline Duration of disease (Years) & 12.29 & 3.66 & 11.5 & 6 & 22 \\
\hline Frequency of transfusion (/Month) & 1.09 & 0.28 & 1 & 1 & 2 \\
\hline Total number of blood transfusions & 151.40 & 45.65 & 139 & 92 & 288 \\
\hline
\end{tabular}

Table II :

\begin{tabular}{|c|c|c|c|c|}
\hline Gender distribution & Chern et al & Amina adil et al & Khalifa et al & Present study \\
\hline Male & 41 & 68 & 32 & 29 \\
\hline Female & 48 & 56 & 24 & 6 \\
\hline M: F ratio & 0.85 & 1.21 & 1.33 & 4.83 \\
\hline Total & $\mathbf{8 9}$ & $\mathbf{1 2 4}$ & $\mathbf{5 6}$ & $\mathbf{3 5}$ \\
\hline
\end{tabular}


Table III

\begin{tabular}{|c|c|c|c|}
\hline \multirow{2}{*}{ Variables } & \multirow{2}{*}{ Sub-groups } & \multicolumn{2}{|c|}{ Total } \\
\hline & & No. & $\%$ \\
\hline \multirow{5}{*}{ Age at Diagnosis (Months) } & 6 or less & 3 & 8.57 \\
\hline & 7 to 12 & 16 & 45.71 \\
\hline & 12 to 18 & 15 & 42.86 \\
\hline & $>18$ & 1 & 2.86 \\
\hline & Total & 35 & 100.00 \\
\hline \multirow{5}{*}{ Duration of disease (Years) } & 5 to 10 & 14 & 40.00 \\
\hline & 11 to 15 & 14 & 40.00 \\
\hline & 16 to 20 & 6 & 17.14 \\
\hline & $>20$ & 1 & 2.86 \\
\hline & Total & 35 & 100.00 \\
\hline \multirow{3}{*}{ Frequency of Transfusion } & 1 & 32 & 91.43 \\
\hline & 2 & 3 & 8.57 \\
\hline & Total & 35 & 100.00 \\
\hline \multirow{9}{*}{ Number of transfusions } & $<100$ & 2 & 5.71 \\
\hline & 100 to 125 & 10 & 28.57 \\
\hline & 126 to 150 & 8 & 22.86 \\
\hline & 151 to 175 & 6 & 17.14 \\
\hline & 176 to 200 & 3 & 8.57 \\
\hline & 201 to 225 & 3 & 8.57 \\
\hline & 226 to 250 & 2 & 5.71 \\
\hline & $>250$ & 1 & 2.86 \\
\hline & Total & 35 & 100.00 \\
\hline \multirow{3}{*}{ Chelation Therapy } & Yes & 25 & 71.43 \\
\hline & No & 10 & 28.57 \\
\hline & Total & 35 & 100.00 \\
\hline
\end{tabular}

\section{Discussion}

$\beta$ thalassemia major is a homozygous state which causes hemolytic anemia demanding regular blood transfusions. The availability of safe blood transfusions with adjuvant chelation therapy has facilitated and extended the survival rates of these patients and now their life expectancy has escalated to fourth and fifth decades. The patient's weight and pre-transfusion hemoglobin and the volume of transfusion should be recorded at each visit. These values should be periodically reviewed to assess the volume of blood required to maintain the desired pre-transfusion hemoglobin level. Alloimmunization is a frequent problem that can be prevented by transfusing blood matched for the patient's extended red blood cell phenotype. An alloantibody screen should be performed prior to each transfusion. The other complications of blood transfusion include the risk of mismatched transfusion, allergic reactions, and febrile, non-hemolytic reactions.
The mean age observed in the present study was close to that of Chern et al. ${ }^{[4]}$ (14.8 \pm 6.9 years) and comparable with the other study from Tehran (15.20 \pm 3.1 years) and a study by Khalifa et al ${ }^{[5]}(15.9 \pm 3.1$ years). In a study by Najafipour $\mathrm{F}$ et al. ${ }^{[6]}$ in Iran reported mean age was 15.62 \pm 4.44 with youngest patient being 10 years and oldest being 27 years. In another study by Khalifa et al ${ }^{[5]}$ showed age range of patients to be 10-30 years as compared to the present study where the age range is $10-23$ years. In the present study majority of the patients $(80 \%)$ were males with male to female ratio of $4: 1$. Similarly, study done by Khalifa et al ${ }^{[5]}$ showed majority of patients were males. The sex distribution pattern observed in the present study was similar to other studies from Kolkata ${ }^{[7]}$ and Rawalpindi. ${ }^{[8]}$ Considering $10 \mathrm{gm} \%$ (in accordance with the moderate transfusion regimen) of pretransfusion hemoglobin as the cut off between adequately transfused and under transfused patients, we found that among those receiving transfusions 
once a month, 100\% were under transfused. Similar percentages for those receiving 1 and 2 transfusions per month were $91.42 \%$, and $8.58 \%$, respectively

The following measures would be optimum for the thalassemia care. Programs that provide acceptable care, including transfusion of safe blood and supportive therapy by chelation, must be established. A careful record of transfused blood should be maintained for each patient, including the volume of the administered units, haematocrit of the donor units and weight of the patient. With this available information, it is possible to calculate transfusion requirements for each patient, which is valuable in early identification of hypersplenism thereby prompting timely splenectomy. Blood transfusion exposes the patient to a variety of risks. Thus, it is vital to continue to improve blood safety and to find ways of reducing transfusion requirements and the number of donor exposures. Adverse events associated with transfusion include: Nonhemolytic febrile transfusion reactions, Allergic reactions, Acute hemolytic reaction, Delayed transfusion reactions, Autoimmune hemolytic anemia, Transfusion-related acute lung injury (TRALI), Transfusion-associated circulatory overload, Transmission of infectious agents including viruses, bacteria and parasites, are a major risk in blood transfusion. ${ }^{[9]}$

\section{Conclusion}

Overall, the present study describes the blood transfusion profile of Beta thalassemia major patients. These patients need comprehensive care. Transfusion record of all Beta thalassemia major patients needs to be maintained regularly in the hospital blood bank for transfusion requirements of patient and also blood bank. The present study critically evaluated the current transfusion regime. Systemic effects of multiple transfusions should be rigorously and meticulously studied.

\section{Acknowledgement}

The authors would like to thank the Department of Pathology and Department of Pediatrics, KLE University's Jawaharlal Nehru Medical College, Belgaum for their support. We also thank Mr. S.V. Virgi of KLES Blood Bank and concerned laboratory personnel for all the assistance in this study.

\section{References}

1. Cao A, Galanello R. Beta thalassemia. Genet Med 2010;12:61-76.

2. Management of birth defects and haemoglobin disorders: Report of a Joint WHO-March of Dimes Meeting. Geneva: World Health Organization; 2006.

3. Sarnaik, AS. Thalassemia and Related Hemoglobinopathies. Indian J Pediatr 2005;72(4):319-24.

4. Chern JP, Su S, Lin KH, Chang SH, Lu MY, Jou ST, et al. Survival, mortality and complications in patients with beta thalassaemia major in northern Taiwan. Pediatr Blood Cancer 2006;47:432-7.

5. Khalifa AS, Salem M, Mounir E, El-Tawil MM, El-Sawy M, Abd Al-Aziz MM. Abnormal glucose tolerance in Egyptian beta-thalassemic patients: possible association with genotyping. Pediatr Diabetes 2004;5:126-32.

6. Najafipour F, Sorkhabi RS, Aghai NH, Zareizadeh M, Bahrami A. Importance of OGTT for diagnosis of Diabetes in thalassemia major patients $\mathrm{J}$ Gorgan Uni Med Sci 2008;10(3):71-6.

7. Mallik S, Chatterjee C, Mandal PK, Sardar JC, Ghosh P, Manna N. Expenditure to Treat Thalassaemia: An Experience at a Tertiary Care Hospital in India. Iranian J Publ Health 2010;39(1):78-84.

8. Rai ME, Tanoli ZM, Gandapur ASK. Clinical spectrum of patients of beta thalassemia: a review of fifty four patients. Glomal J Medical sciences 2005;3(2):55-60.

9. Guidelines for the Clinical Management of Thalassaemia. 2nd Revised ed., No. 9, Nicosia (CY): Thalassaemia International Federation; 2008.

*Corresponding author:

Dr. Mallikarjun .A. Pattanashetti , Assistant Professor, Department of Pathology, S. Nijalingappa Medical College and HSK Hospital \& MRC

Bagalkot, Karnataka, India

Email: mallikarjun2030@gmail.com

Date of Submission : 08.01.2017

Date of Acceptance : 28.01.2017

Financial or other Competing Interests: None. 